\title{
Mechanistic investigation of immunosuppression in patients with condyloma acuminata
}

\author{
YU-JIE SHI, JIAN YANG and WENLIN YANG \\ Department of Dermatology, The Second Affiliated Hospital of Guangzhou Medical University, \\ Guangzhou, Guangdong 510260, P.R. China
}

Received January 9, 2013; Accepted April 25, 2013

DOI: $10.3892 / \mathrm{mmr} .2013 .1511$

\begin{abstract}
Condyloma acuminatum (CA) is a common sexually transmitted disease caused by human papillomavirus (HPV) infection. Previous studies have identified that the occurrence, relapse and cancerization of CA is relevant to immune imbalance caused by immune hypofunction or immunoregulatory dysfunction. However, to date, the specific mechanisms accounting for immune imbalance in CA patients have remained elusive. In the present study, changes in the expression levels of myeloid differentiation factor 88 (MyD88) and toll-like receptors (TLRs) were determined in lesion tissues and peripheral blood samples obtained from CA patients by fluorescence quantitative PCR and western blot analysis. The results indicated that TLRs and MyD88 expression was upregulated in the lesion tissues only. In addition, the expression of forkhead box P3, a characteristic marker of regulatory $\mathrm{T}$ cells (Tregs), transforming growth factor- $\beta 1$ and interleukin (IL)-10, inhibitory factors secreted by Tregs and inhibitory costimulatory molecules, cytotoxic T-lymphocyte antigen 4, glucocorticoid-induced TNFR-related protein and programmed cell death protein 1 was observed to be upregulated, indicating that immunosuppression of Tregs was enhanced significantly. However, the expression levels of NKG2D and NKp46, natural killer (NK) cell activation receptors located on the surface of NK cells, decreased markedly indicating that HPV infection inhibits the activation of NK cells. The secretion levels of various cytokines in the peripheral blood of CA patients were detected by enzyme-linked immunosorbent assay revealing that IL-2, IL-12 and interferon- $\gamma$ levels were markedly lower than that of healthy subjects. By contrast, the expression levels of tumor necrosis factor- $\alpha$, IL-4 and IL-10 were markedly increased in CA samples compared
\end{abstract}

Correspondence to: Dr Yu-Jie Shi, Department of Dermatology, The Second Affiliated Hospital of Guangzhou Medical University, 250 Changgang East Road, Guangzhou, Guangdong 510260, P.R. China

E-mail: shiyujie139@yahoo.com.cn

Key words: condyloma acuminatum, human papillomavirus, MyD88, toll-like receptor with the control, with the exception of IL-6. Taken together, these results are consistent with the hypothesis of immunosuppression in CA patients. Increased expression of MyD88 and TLRs is likely to enhance immunosuppression of Tregs, leading to the imbalance of Th1/Th2, cytotoxic T cell type 1 $(\mathrm{Tc} 1) / \mathrm{Tc} 2$ cells and secreted cytokines.

\section{Introduction}

Condyloma acuminatum (CA) is caused by human papillomavirus (HPV) infection and has become one of the most common sexually transmitted diseases worldwide. Since the early 1980s, the clinical identification of HPV infections have sharply increased. In addition, relapse rates following the administration of existing treatments have continued to rise and to date, attempts to eradicate HPV infection have failed (1). Studies have reported that the relapse rate of HPV-induced CA has increased to $60-70 \%$ (2). Furthermore, recurrent HPV infection has been reported to be closely associated with cervical, vulvar and anal carcinomas, and other types of genital tumor (3). Therefore, the control of HPV infection has become an important issue and of interest to scientists in the fields of medicine, pharmacology and biology.

Toll-like receptors (TLRs) are one of the most important types of pathogen recognition receptors in natural immunity, functioning as bridges in the innate and specific immunity systems (4). TLRs selectively recognize pathogen-associated molecular patterns (PAMPs) carried by pathogenic microorganisms. Recognition of PAMPs leads to the initiation of signal transduction and induction of the activation and maturation of macrophages and dendritic cells (DCs), promoting the secretion of cytokines by these cells which activates the immune response and the acquired immune system. TLR family members, TLR2, TLR3, TLR4, TLR7, TLR8 and TLR9, are the main receptors involved in viral recognition. TLR2 and TLR4 recognize viral envelope glycoproteins, TLR3 identifies double-stranded RNA viruses, TLR7/8 largely identifies single-stranded RNA viruses and TLR9 discerns the CpG DNA sequence in viral chromosome genes (5). Myeloid differentiation factor 88 (MyD88), a key adapter molecule in TLR signal transduction, is responsible for the initiation of downstream signaling pathways (6). However, at present, few studies have aimed to determine the role of the TLR/MyD88 signaling pathway in the resistance of HPV. Therefore, the 
significance of TLR/MyD88 in the anti-HPV process must be investigated.

Previous studies have demonstrated that the occurrence, remission, relapse and cancerization of CA is associated with immune imbalance caused by immune hypofunction or immunoregulatory disorders in patients (7). At present, studies on the infection process of HPV in humans have indicated that hosts are capable of generating a certain degree of humoral and cell-mediated immunity; however, this immunity is far from sufficient to clear the virus. In addition, immune status studies of local lesions revealed that HPV-infected patients often suffer from systemic or local immune dysfunction or defects. Studies have reported that the downregulation of major histocompatibility complex I and II in local lesions, alternation of the ratio of $\mathrm{CD}^{+}$and $\mathrm{CD}^{+} \mathrm{T}$ lymphocytes, decrease in expression of tumor necrosis factor (TNF)- $\alpha$, GM-CSF, interleukin (IL)- $1 \alpha$ and IL- $1 \beta$, increased expression of IL-10, the dysfunction and decreased number of langerhans cells and expression defects of costimulatory molecules, result in the inhibition of HPV antigen presentation followed by inhibition of T-lymphocyte activation $(8,9)$. Therefore, specific immunity may not be induced to clear HPV. The correlation between HPV infection and hypoergia of the immune system to viral antigens remains unclear, making it difficult to investigate the pathological mechanisms and therapeutic strategies of HPV infection. In recent years, further exploration of the biological characteristics and functions of regulatory $\mathrm{T}$ cells (Tregs) have revealed that the presence of abnormal Tregs may be involved in HPV infection. For instance, overexpression of Tregs may contribute to immunosuppression in local lesions of HPV and lead to the overexpression of membrane molecules, IL-10 and transforming growth factor (TGF)- $\beta$, without causing abnormal changes in the number of $\mathrm{CD}^{+}$ T lymphocytes (10). Therefore, the present study aimed to investigate the possible mechanisms of immunosuppression in CA patients by analyzing the expression levels of TLRs, MyD88 and Treg-related factors and changes in cytokine levels in CA patients.

\section{Materials and methods}

Clinical data. CA wart lesions and blood specimens were obtained from dermatology outpatients at the Second Affiliated Hospital of Guangzhou Medical College (Guangdong, China) and were consistent with diagnostic criteria of CA (11) and confirmed by histopathological examination. Patients had no medical history of systemic antiviral drugs or immunomodulators two weeks prior to treatment. Patients with autoimmune, severe systemic or other infectious diseases were excluded from the study. Subjects included 26 males and 18 females with an average age of $33.9 \pm 11.0(20-56)$ years and average disease duration of 97.24 152.1 (4-320) days, among which 28 were newly diagnosed and 16 cases were relapsed. Lesions of 40 specimens were obtained from male foreskin, corona of glans penis, perianal region, female pudendum and perianal region, and stored in liquid nitrogen. In addition, $5 \mathrm{ml}$ venous blood was sampled routinely and stored at $-20^{\circ} \mathrm{C}$ following isolation of mononuclear cells. Among 40 specimens of the control group, 20 specimens were normal foreskin from circumcision procedures performed in our hospital (The Second Affiliated
Hospital of Guangzhou Medical University) and another 20 were blood samples obtained from healthy subjects. The gender and age differences between the groups were of no statistical significance. This study was approved by the hospital ethics committee and informed consent was obtained from all patients.

Fluorescence quantitative PCR. Wart tissue was ground into a fine powder in liquid nitrogen and peripheral blood mononuclear cells were separated by lymphocyte separation medium. Total RNA was extracted using TRIzol (Invitrogen Life Technologies, Carlsbad, CA, USA) according to the manufacturer's instructions. RNA integrity was detected by electrophoresis and quantitative determination was performed, followed by reverse transcription using the One Step SYBR PrimeScript RT-PCR kit (Takara Bio, Inc., Shiga, Japan). The reaction was performed using the ABI PRISM 7500 Real-Time PCR System (Life Technologies, China) at $42^{\circ} \mathrm{C}$ for $5 \mathrm{~min}, 95^{\circ} \mathrm{C}$ for $10 \mathrm{sec}$; then 40 cycles of $95^{\circ} \mathrm{C}$ for $5 \mathrm{sec}, 55^{\circ} \mathrm{C}$ for $30 \mathrm{sec}$ and $72^{\circ} \mathrm{C}$ for $30 \mathrm{sec}$. The primers used for quantitative determination are presented in Table I, among which TLR primer sequences were obtained from Daud et al (12). Each specimen was analyzed in triplicate and quantification was derived using the $2^{-\Delta \Delta \mathrm{Ct}}$ method.

Western blot analysis. Total cellular proteins were extracted by incubating $100 \mathrm{mg}$ ground tissue specimens in lysis buffer. Protein concentrations in the lysates were determined by Quick Start Bradford Protein assay (Bio-Rad, Hercules, CA, USA). SDS-PAGE was performed in $12 \%$ glycine gels (Bio-Rad), loading equal amounts of proteins per lane. Following electrophoresis, separated proteins were transferred onto a PVDF membrane and blocked with 5\% non-fat milk. Next, membranes were incubated with antibodies against MyD88 (1:500), TLR2 (1:400), TLR3 (1:500), TLR4 (1:500), TLR7 (1:200) TLR8 (1:500), TLR9 (1:250), forkhead box P3 (FOXP3; 1:250), TGFß1 (1: 500), IL-10 (1:800), cytotoxic T-lymphocyte antigen 4 (CTLA4; 1:1,000), GITR (1:200), programmed cell death protein 1 (PD1; 1:50), NKG2D (1:200), NCR1 (1:200) and GAPDH (1:1,000; all antibodies were purchased from Abcam, Cambridge, UK) in 5\% non-fat milk overnight at $4^{\circ} \mathrm{C}$ and then goat anti-rabbit IgG monoclonal antibody (Santa Cruz Biotechnology, Inc., Santa Cruz, CA, USA) conjugated with horseradish peroxidase. Protein bands were detected using the West Femto system (Pierce Biotechnology, Inc., Rockford, IL, USA).

Enzyme-linked immunosorbent assay (ELISA). Peripheral blood mononuclear cells were separated by lymphocyte separation medium. IL-2, IL-4, IL-6, IL-10, IL-12, TNF- $\alpha$ and interferon (IFN) $-\gamma$ levels were detected according to the manufacturer's instructions by ELISA (Insight Genomics, Falls Church, VA, USA).

Statistical analysis. Experiments were performed at least in triplicate and repeated three times. All data are expressed as the mean \pm SD. Statistical analysis was performed using SPSS statistical package (SPSS 13.0 for Windows; SPSS, Inc., Chicago, IL, USA). The difference between two groups was analyzed by two-tailed Student's t-test. The difference between 
Table I. Primers for quantitative PCR.

\begin{tabular}{|c|c|c|c|c|}
\hline Primer name & Direction & Primer sequence $\left(5^{\prime}-3^{\prime}\right)$ & Primer size (bp) & $\begin{array}{c}\text { GenBank } \\
\text { accession number }\end{array}$ \\
\hline \multirow[t]{2}{*}{ MyD88 } & F & CAGAGCAAGGAATGTGACTTC & \multirow[t]{2}{*}{140} & \multirow[t]{2}{*}{ NM_001172567 } \\
\hline & $\mathrm{R}$ & TCGCAGACAGTGATGAACC & & \\
\hline \multirow[t]{2}{*}{ TLR2 } & F & AACCGGAGAGACTTTGCTCA & \multirow[t]{2}{*}{91} & \multirow[t]{2}{*}{ NM_003264 } \\
\hline & $\mathrm{R}$ & CCACTGACAAGTTTCAGGCA & & \\
\hline \multirow[t]{2}{*}{ TLR3 } & $\mathrm{F}$ & CCTGGTTTGTTAATTGGATTAACGA & \multirow[t]{2}{*}{82} & \multirow[t]{2}{*}{ NM_003265 } \\
\hline & $\mathrm{R}$ & TGAGGTGGAGTGTTGCAAAGG & & \\
\hline \multirow[t]{2}{*}{ TLR4 } & $\mathrm{F}$ & GGACTGGGTAAGGAATGAGCTAGTA & \multirow[t]{2}{*}{94} & \multirow[t]{2}{*}{ NM_138554 } \\
\hline & $\mathrm{R}$ & CACACCGGGAATAAAGTCTCTGT & & \\
\hline \multirow[t]{2}{*}{ TLR7 } & $\mathrm{F}$ & AAGCCCTTTCAGAAGTCCAAGTT & \multirow[t]{2}{*}{91} & \multirow[t]{2}{*}{ NM_016562 } \\
\hline & $\mathrm{R}$ & GGTGAGCTTGCGGGTTTGT & & \\
\hline \multirow[t]{2}{*}{ TLR8 } & $\mathrm{F}$ & GCTGCTGCAAGTTACGGAAT & \multirow[t]{2}{*}{118} & \multirow[t]{2}{*}{ NM_016610 } \\
\hline & $\mathrm{R}$ & CGCATAACTCACAGGAACCA & & \\
\hline \multirow[t]{2}{*}{ TLR9 } & $\mathrm{F}$ & TGAAGACTTCAGGCCCAACTG & \multirow[t]{2}{*}{75} & \multirow[t]{2}{*}{ NM_017442 } \\
\hline & $\mathrm{R}$ & TGCACGGTCACCAGGTTGT & & \\
\hline \multirow{2}{*}{ FOXP3 } & $\mathrm{F}$ & GAAGCAGCGGACACTCAATG & \multirow[t]{2}{*}{106} & \multirow[t]{2}{*}{ NM_014009 } \\
\hline & $\mathrm{R}$ & ACTCAGGTTGTGGCGGATG & & \\
\hline \multirow{2}{*}{ TGFB1 } & $\mathrm{F}$ & CTGAACCCGTGTTGCTCTC & \multirow[t]{2}{*}{112} & \multirow{2}{*}{ NM_000660 } \\
\hline & $\mathrm{R}$ & AGGTATCGCCAGGAATTGTTG & & \\
\hline \multirow{2}{*}{ IL-10 } & $\mathrm{F}$ & AACCAAGACCCAGACATC & \multirow[t]{2}{*}{135} & \multirow{2}{*}{ NM_000572 } \\
\hline & $\mathrm{R}$ & ATTCTTCACСТGCTCCAC & & \\
\hline CTLA4 & $\mathrm{F}$ & TTCTCTTCATCCCTGTCTTCTG & 127 & NM_005214 \\
\hline & $\mathrm{R}$ & CGGACCTCAGTGGCTTTG & & \\
\hline GITR & $\mathrm{F}$ & AATTCCACTGCGGAGACC & 120 & NM_004195 \\
\hline & $\mathrm{R}$ & CCGAGGCACAGTCGATAC & & \\
\hline PD-1 & $\mathrm{F}$ & CCAGGATGGTTCTTAGACTC & 128 & NM_005018 \\
\hline & $\mathrm{R}$ & AAGCTCTCCGATGTGTTG & & \\
\hline NKG2D & $\mathrm{F}$ & TCССТCTCTGAGCAGGAATCC & 107 & NM_007360 \\
\hline & $\mathrm{R}$ & AGACCTCCGACCACGAATCC & & \\
\hline NKp46 & $\mathrm{F}$ & CCGAGGGACATACCGATG & 106 & NM_004829 \\
\hline & $\mathrm{R}$ & AAGGCTGGTGTTCTCAATG & & \\
\hline GAPDH & $\mathrm{F}$ & GGTATCGTGGAAGGACTC & 128 & NM_002046 \\
\hline & $\mathrm{R}$ & GTAGAGGCAGGGATGATG & & \\
\hline
\end{tabular}

MyD88, myeloid differentiation factor 88; TLR, toll-like receptor; FOXP3, forkhead box P3; TGF, transforming growth factor; IL, interleukin; CTLA4, cytotoxic T-lymphocyte antigen 4; GITR, glucocorticoid-induced TNFR-related protein; PD-1, programmed cell death protein 1; $\mathrm{F}$, forward; $\mathrm{R}$, reverse.

three or more groups was analyzed by one-way analysis of variance multiple comparisons. $\mathrm{P}<0.05$ was considered to indicate a statistically significant difference.

\section{Results}

Expression of MyD88 and TLRs increases in the lesion tissues of $C A$ patients. Changes in the expression levels of MyD88 and TLRs were detected by quantitative PCR and western blot analysis. The results revealed that the expression of MyD88 and TLRs increased markedly in the lesion tissues of CA patients compared with those of normal specimens (Figs. 1 and 2); however, changes in peripheral blood were not detected, indicating that HPV infection activated the local immune system only and the immune response was confined to viral infection sites. We have previously showed that, by comparing with normal epidermis, stratum spinosum cells in CA lesions were significantly thickened and MyD88 expression was increased (13). In addition, MyD88 was expressed in the whole epidermal layer, and particularly overexpressed in the basal layer (13). Increased expression of MyD88 and TLRs contributed to enhanced downstream signaling effects and cellular immune function. However, the current study demonstrated that, in addition to expression in effector cells of the innate immune system which mediates the anti-pathogen reaction, TLRs are also expressed in T- and B-lymphocytes of the adaptive immune system. $\mathrm{CD}^{+}$and $\mathrm{CD} 25^{+}$Tregs mainly exerted negative regulatory roles in the immune response to inhibit the proliferation and activation of effector cells (18). TLR1-9 were expressed in Tregs at different degrees. Therefore, it is likely 

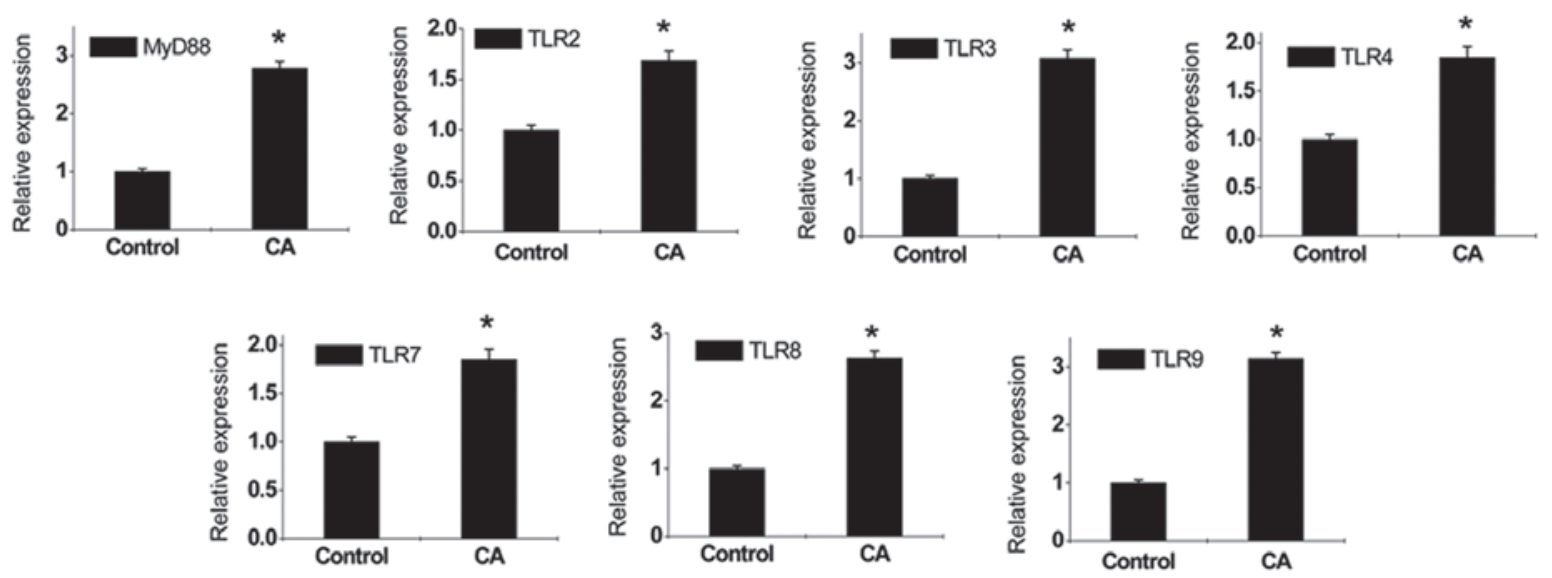

Figure 1. Quantitative PCR analysis of mRNA expression of MyD88 and TLRs in CA patient lesion tissues and healthy foreskins. Each bar represents the mean \pm SD of at least 3 samples. GAPDH served as a loading control. "P<0.05, vs. control. CA, condyloma acuminata; MyD88, myeloid differentiation factor 88; TLR, toll-like receptor.
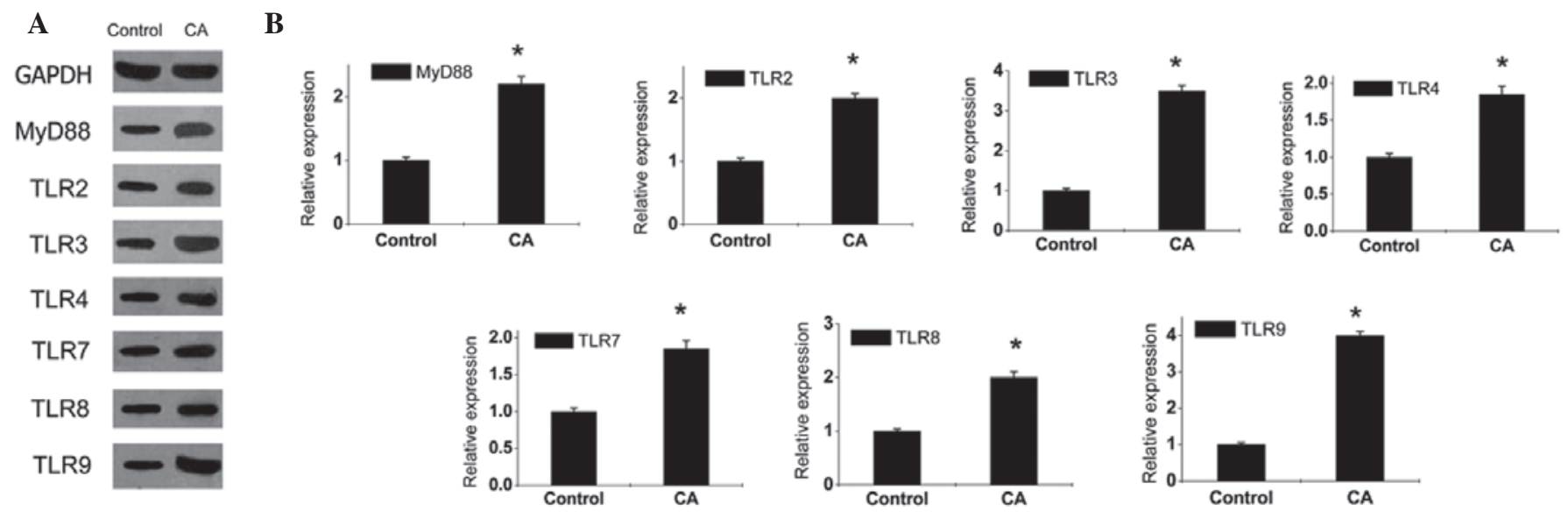

Figure 2. (A) Western blotting and (B) quantitative analysis of protein expression of MyD88 and TLRs in CA patient lesion tissues and healthy foreskins. Each bar represents the mean \pm SD of at least 3 samples. GAPDH served as a loading control. ${ }^{*}<<0.05$, vs. control. CA, condyloma acuminata; MyD88, myeloid differentiation factor 88 ; TLR, toll-like receptor.

that increased expression of TLRs enhances Treg function leading to immunosuppression.

Expression levels of Treg-related factor, Foxp3, NKG2D and NKp46 in CA lesion tissues. Results of quantitative PCR and western blot analysis demonstrated that the expression of Foxp3, a characteristic marker of Tregs and several inhibitory costimulatory molecules, including CTLA-4, glucocorticoidinduced TNFR-related protein (GITR) and PD-1, was markedly increased in the lesion tissues of CA patients (Figs. 3 and 4) compared with controls, indicative of a significantly enhanced immunosuppressive function in Tregs. In addition, Foxp $3^{+} \mathrm{CD} 4^{+} \mathrm{CD} 25^{+}$Tregs largely mediated suppression via direct interaction between cells and secretion of the inhibitory factors, TGF- $\beta 1$ and IL- 10 . In addition, results of quantitative PCR and western blot analysis revealed a marked increase in TGF- $\beta 1$ and IL-10 levels (Figs. 3 and 4). The expression of NKG2D and NKp46, which activate specific natural killer (NK) cell surface receptors, decreased markedly, indicating that HPV infection downregulates the expression of activated receptors of NK cells and suppresses activation of NK cells.
CA patients exhibit an imbalance of Th1/Th2, Tc1/Tc2 and secreted cytokines. Helper T lymphocyte subsets (Th1/Th2) are important for anti-HPV immunity, since the Th1 response, which is involved in cellular immunity, is the main immune response following HPV infection (14). $\mathrm{CD}^{+} \mathrm{T}$ cells, known as cytotoxic T cells, are vital for the antiviral cellular immune response which directly kills the target cells infected by the virus. Similar to $\mathrm{CD}^{+}$helper $\mathrm{T}$ cells, Tc subsets of $\mathrm{CD} 8^{+}$ $\mathrm{T}$ cells are divided into Tc1 and Tc2 subsets. Tc1 and Th1 secrete IFN- $\gamma$, IL-2, IL-12 and several other cytokines which mediate cellular immunity. Similarly, Tc2 and Th2 secrete IL-4, IL-5, IL-6, IL-10 and several other cytokines which mediate humoral immunity. In the present study, ELISA was performed to detect the secretion levels of cytokines in the peripheral blood of CA patients. IL-2, IL-12 and IFN- $\gamma$ levels were markedly lower than those of control subjects; however, TNF- $\alpha$ levels were increased. In addition, levels of IL-4 and IL-10 were increased, and IL-6 was decreased compared with control patients (Fig. 5). Decreased levels of Th1-type cytokines and increased Th2-type cytokines are indicative of cellular immune suppression in CA patients. 

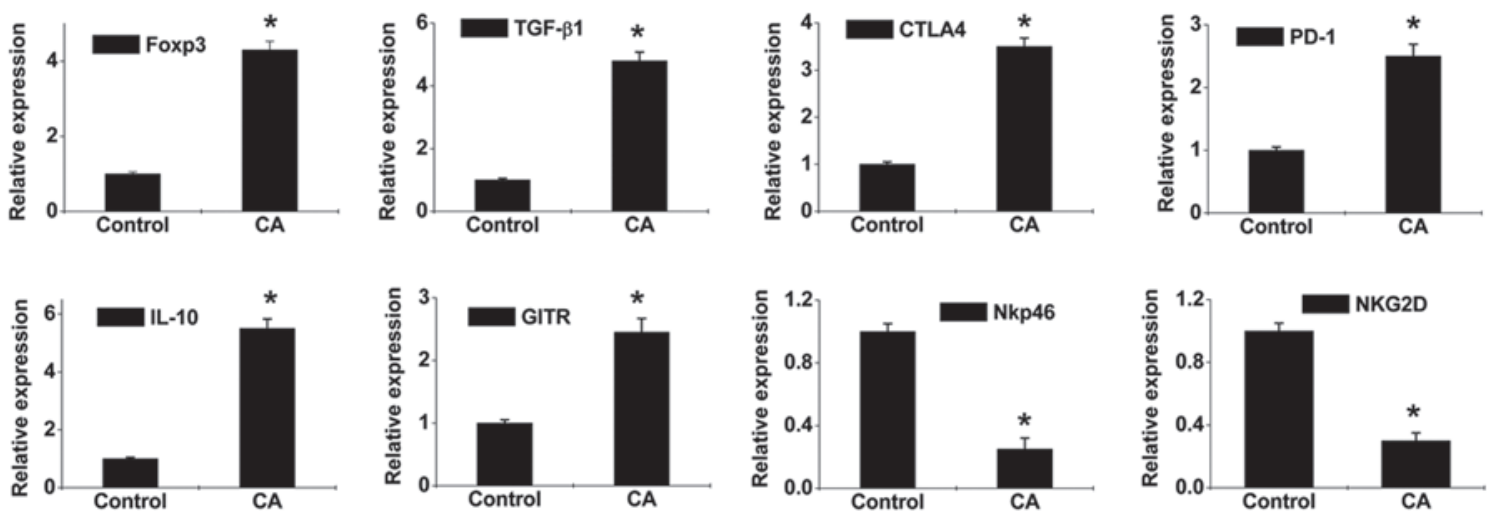

Figure 3. Quantitative PCR analysis of the mRNA expression of Treg cell-related factors and NKG2D and NKp46 in CA patient lesion tissues and healthy foreskins. Each bar represents the mean \pm SD of at least 3 samples. GAPDH served as a loading control. " $\mathrm{P}<0.05$, vs. control. Treg, regulatory T cell; CA, condyloma acuminata; FOXP3, forkhead box P3; TGF, transforming growth factor; IL, interleukin; CTLA4, cytotoxic T-lymphocyte antigen 4; PD-1, programmed cell death protein 1; GITR, glucocorticoid-induced TNFR-related protein.
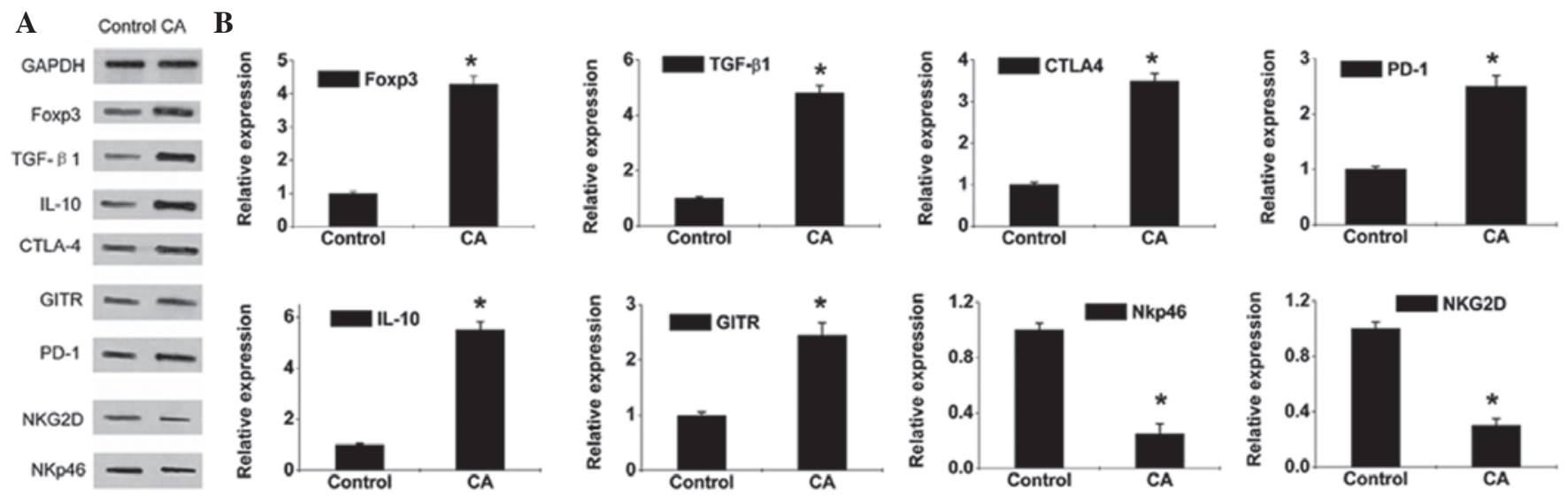

Figure 4. (A) Western blotting and (B) quantitative analysis of the protein expression of Treg cell-related factors and NKG2D and NKp46 in CA patient lesion tissues and healthy foreskins. Each bar represents the mean \pm SD of at least 3 samples. GAPDH served as a loading control. ${ }^{*} \mathrm{P}<0.05$, vs. control. Treg, regulatory T cell; CA, condyloma acuminata; Foxp3, forkhead box P3; TGF, transforming growth factor; IL, interleukin; CTLA4, cytotoxic T-lymphocyte antigen 4; PD-1, programmed cell death protein 1; GITR, glucocorticoid-induced TNFR-related protein.

A

B
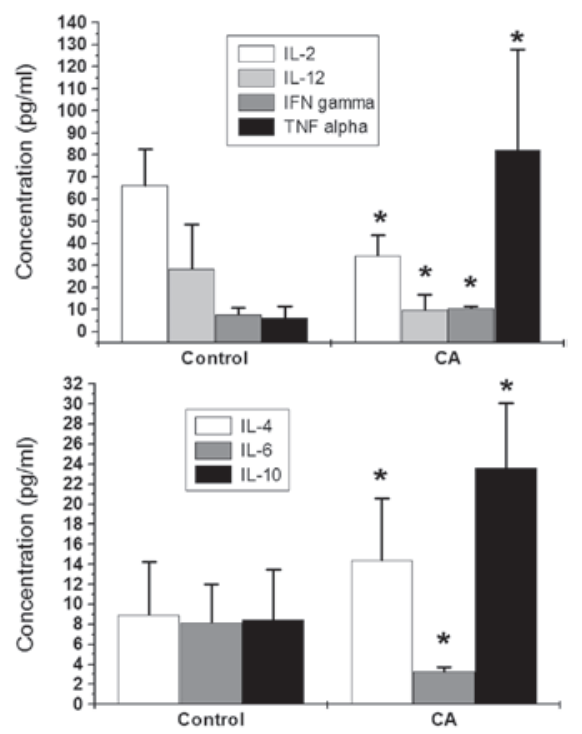

Figure 5. Levels of secreted cytokines in the peripheral blood of CA patients were determined by ELISA. (A) IL-2, IL-12, IFN- $\gamma$ and TNF- $\alpha$. (B) IL-4, IL-6 and IL-10. The results are presented as the mean \pm SD $(n=3)$. "P<0.01 vs. control. ELISA, enzyme-linked immunosorbent assay; CA, condyloma acuminata; IL, interleukin; IFN, interferon; TNF, tumor necrosis factor.

\section{Discussion}

In recent years, the morbidity of CA has risen and the clinical relapse rate has increased. In addition, several types of HPV infection have been closely associated with malignant cancer of the cervix, vulva and vagina, as well as precancerous atypical hyperplasia (15). Increasing public and clinical concern has meant that the control and understanding of HPV infection has become an important issue. A number of previous studies have demonstrated that increased expression of MyD88 and TLRs is associated with HPV infection, which may activate MyD88-dependent signaling pathways in the lesion tissues of CA patients. Upregulation of MyD88 and TLRs has been identified to contribute to enhanced downstream signal transduction and cellular immune function, which promote the recognition and clearance of the virus by the body. Through RT-PCR and immunohistochemistry, Ku et al (16) found that the expression of TLR3 and TLR9 in verruca plana and molluscum contagiosum lesions was enhanced compared with healthy epidermis. Yang et al (17) found that HPV activated TLR9 via the MyD88 pathway to stimulate the generation of the Th1-type immune response by DCs, which was crucial to 
anti-HPV16 infection. In addition, Daud et al (12) reported that clearance of HPV16 infections was significantly associated with increased expression of the four viral nucleic acid-sensing TLRs (TLR3, TLR7, TLR8 and TLR9), as well as TLR2, upon viral acquisition. Based on these observations, the authors concluded that, reduced TLR expression in the cervical mucosa was caused by a type-specific mechanism in which HPV16 interfered with the innate immune response and contributed to viral persistence. In addition, the upregulation of TLR was involved in subsequent viral clearance. Therefore, the MyD88-dependent signaling pathway is vital for resistance to HPV infection.

TLRs additionally directly modulate the adaptive immune response. The activation of Tregs, a T-cell subset, effectively inhibits the immune response of $\mathrm{CD}^{+}$and $\mathrm{CD}^{+} \mathrm{T}$ effector cells, exerting negative immunomodulatory effects (18). Expression levels of TLRs in human and rat $\mathrm{CD} 4{ }^{+} \mathrm{CD} 25^{+}$ Tregs are higher than that of $\mathrm{CD}^{+} \mathrm{T}$ cells. In the present study, specific TLRs, including TLR2, TLR8 and TLR9, were observed to modulate the function of $\mathrm{CD} 4{ }^{+} \mathrm{CD} 25^{+}$Tregs and eliminate or reverse the immune suppression effect of CD $4{ }^{+} \mathrm{CD} 25^{+}$Tregs, while TLR2, TLR4 and TLR5 mediated the opposite effect (19). Thus, in addition to activation of antigen-presenting cells and costimulation of effector $\mathrm{T}$ cells, TLRs affect the proliferation and function of Tregs (20), which may represent one of the mechanisms of immune suppression in CA patients. Examination of the expression of MyD88 and TLRs in peripheral blood samples of CA patients revealed no significant difference in healthy subjects, indicating that HPV infection is unable to activate the systemic immune response.

Foxp3, a specific marker of Tregs, is essential for $\mathrm{CD} 4{ }^{+} \mathrm{CD} 25^{+}$Treg differentiation and development in the thymus (21). Foxp3 expression in peripheral $\mathrm{T}$ cells is required for preventing autoimmunity and possibly for TR cell maintenance. Foxp3 determines the inhibitory functions of Tregs and this function has been hypothesized to be mediated at the level of translation (22). To regulate the cell-mediated immune protective effect and form sustained infection, Tregs suppress the activation and proliferation of $\mathrm{T}$ cells by inhibiting transcription and expression of $\mathrm{IL}-2$ in $\mathrm{CD}^{+}$and $\mathrm{CD} 8^{+}$cells, regulating the intensity levels of the antiviral immune response by controlling the differentiation of Th1 and Th2 cells induced by DCs. The mode of suppressive action of Tregs on immune cells is divided into two categories, cytokine-secreting and cell contact inhibition, both of which mainly target effector $\mathrm{T}$ cells. Cytokine-secreting inhibition includes TGF- $\beta 1$ and IL-10 signaling pathway-mediated immunosuppression, while cell contact inhibition is primarily mediated by CTLA-4 (23). Results of quantitative PCR and western blot analysis demonstrated a marked increase in the expression of Foxp3, TGF- $\beta 1$, IL-10, CTLA4, GITR and PD-1, indicative of an enhanced function of Tregs. In addition, TGF- $\beta 1$ induces Foxp3 expression and transforms initial peripheral $\mathrm{CD} 4^{+} \mathrm{CD} 25^{-} \mathrm{T}$ cells into $\mathrm{CD} 4{ }^{+} \mathrm{CD} 25^{+}$Tregs, maintaining the number and function of $\mathrm{CD} 4^{+} \mathrm{CD} 25^{+} \mathrm{T}$ cells (24). The expression levels of CTLA-4, GITR and PD-1 serve as negative co stimulatory molecules under high expression levels of transduction inhibition signals. Although without specificity, the change in the expression levels of CTLA-4, GITR and PD-1 may directly or indirectly reflect the function of Tregs. Several studies have demon- strated that the number of Tregs increase in the peripheral blood of persistently HPV16-infected patients and CIN3 level patients (25). Similarly, Foxp $3^{+}$Tregs in the peripheral blood of CA patients are enhanced compared with healthy subjects and this observation is particularly evident in relapsed patients (14). Simultaneously, expression levels of NKG2D and NKp46, which function as activated receptors on the surface of $\mathrm{NK}$ cells, reduce markedly, revealing that reduced NK cell activity results in a reduced ability to clear viral infections in vivo.

Sun et al (26) reported that TLR-mediated activation of DCs may transmit negative regulatory signals to inhibit the Th2 response in a MyD88-dependent manner. By stimulating marrow-derived DCs from wild-type and MyD88-deficient mice with LPS and co-culturing with $\mathrm{CD}^{+} \mathrm{T}$ cells, Kaisho et al (27) found that wild-type DCs promoted the secretion of IFN- $\gamma$ and IL-12; however, inhibited the secretion of IL-4 by CD4 ${ }^{+} \mathrm{T}$ cells following stimulation with LPS. By contrast, MyD88-deficient DCs did not induce secretion of IFN- $\gamma$ and IL-12 by CD $4^{+} \mathrm{T}$ cells, but significantly promoted the secretion of IL-4. Therefore, increased expression of MyD88 and TLRs was expected to promote the generation of Th1-type cytokines; however, in the present study, opposite results were obtained. Levels of secreted cytokines were detected by ELISA in peripheral blood samples obtained from CA patients. Levels of Th1-type cytokines, IL-2, IL-12 and IFN- $\gamma$, were markedly reduced compared with healthy subjects; however, TNF- $\alpha$ levels were increased. In addition, Th2-type cytokines, IL-4 and IL-10, were increased in CA patients compared with the control, and IL-6 levels were decreased. The overall decrease in Th1-type cytokines and increase in Th2-type cytokines is indicative of cellular immune suppression in CA patients. Bais et al (28) hypothesized that disequilibrium of Th1/Th2 in HPV-infected individuals may affect correct activation of Langerhans cells, leading to activation failure and subsequent dysfunction of Tc cellular immunity. Cao et al (10) found that the immunosuppressive environment in large warts was characterized by high expression of IL-10 and TGF- $\beta 1$, and low expression of IL-2 and IFN- $\gamma$. Similarly, Xu et al (14) reported that patients with CA were observed to exhibit a decreased proportion of Th1 and Tc1 cells, and a decreased ratio of Th1/Th2 and Tc1/Tc2. Consequently, the switch of the Th1-type immune response towards a Th2 type may represent a mechanism by which HPV evades the immune response.

In summary, enhanced expression of TLRs and MyD88 in CA tissues may promote the immune suppressive function of Tregs, leading to immunosuppression and sustained HPV infection.

\section{References}

1. O'Mahony C: Genital warts: current and future management options. Am J Clin Dermatol 6: 239-243, 2005.

2. McMurray HR, Nguyen D, Westbrook TF and McAnce DJ: Biology of human papillomaviruses. Int J Exp Pathol 82: 15-33, 2001.

3. Partridge JM and Koutsky LA: Genital human papillomavirus infection in men. Lancet Infect Dis 6: 21-31, 2006.

4. Akira S and Takeda K: Toll-like receptor signalling. Nat Rev Immunol 4: 499-511, 2004.

5. Xagorari A and Chlichlia K: Toll-like receptors and viruses: induction of innate antiviral immune responses. Open Microbiol J 2: 49-59, 2008. 
6. Sin JI: MyD88 signal is required for more efficient induction of Ag-specific adaptive immune responses and antitumor resistance in a human papillomavirus E7 DNA vaccine model. Vaccine 29: 4125-4131, 2011

7. Ahmed AM, Madkan V and Tyring SK: Human papillomaviruses and genital disease. Dermatol Clin 24: 157-165, 2006.

8. Narayan S, Choyce A, Linedale R, et al: Epithelial expression of human papillomavirus type $16 \mathrm{E} 7$ protein results in peripheral CD8 T-cell suppression mediated by $\mathrm{CD} 4{ }^{+} \mathrm{CD} 25^{+} \mathrm{T}$ cells. Eur J Immunol 39: 481-490, 2009.

9. Liu XS, Leerberg J, MacDonald K, Leggatt GR and Frazer IH: IFN-gamma promotes generation of IL-10 secreting CD $4^{+} \mathrm{T}$ cells that suppress generation of CD8 responses in an antigen-experienced host. J Immunol 183: 51-58, 2009.

10. Cao Y, Zhao J, Lei Z, et al: Local accumulation of FOXP3 ${ }^{+}$regulatory $\mathrm{T}$ cells: evidence for an immune evasion mechanism in patients with large condylomata acuminata. J Immunol 180: 7681-7686, 2008.

11. Del Mistro A, Koss LG, Braunstein J, Bennett B, Saccomano G and Simons KM: Condylomata acuminata of the urinary bladder. Natural history, viral typing and DNA content. Am J Surg Pathol 12: 205-215, 1988

12. Daud II, Scott ME, Ma Y, Shiboski S, Farhat S and Moscicki AB: Association between toll-like receptor expression and human papillomavirus type 16 persistence. Int J Cancer 128: 879-886, 2011.

13. Shi YJ, Xiong F, Yang J, et al: The expression and significance of MyD88 in condyloma acuminatum. Zhong Guo PiFu Xing Bing Xue Za Zhi 24: 626-628, 2010 (In Chinese).

14. Xu Y, Zhu KJ, Zhu N, Jiang DH, Chen XZ and Cheng H: Expression of Foxp $3{ }^{+} \mathrm{CD} 4{ }^{+} \mathrm{CD} 25^{+}$regulatory $\mathrm{T}$ cells and Th1/Th2, Tc1/Tc2 profiles in the peripheral blood of patients with condyloma acuminatum. Clin Exp Dermatol 34: 229-235, 2009.

15. Villa LL, Costa RL, Petta CA, et al: High sustained efficacy of a prophylactic quadrivalent human papillomavirus types 6/11/16/18 L1 virus-like particle vaccine through 5 years of follow-up. Br J Cancer 95: 1459-1466, 2006.

16. Ku JK, Kwon HJ, Kim MY, et al: Expression of Toll-like receptors in verruca and molluscum contagiosum. J Korean Med Sci 23: 307-314, 2008.
17. Yang R, Murillo FM, Cui H, et al: Papillomavirus-like particles stimulate murine bone marrow-derived dendritic cells to produce alpha interferon and Th1 immune responses via MyD88. J Virol 78: 11152-11160, 2004

18. Ochs HD, Gambineri E and Torgerson TR: IPEX, FOXP3 and regulatory T-cells: a model for autoimmunity. Immunol Res 38: 112-121, 2007.

19. van Maren WW, Jacobs JF, de Vries IJ, Nierkens S and Adema GJ: Toll-like receptor signalling on Tregs: to suppress or not to suppress? Immunology 124: 445-452, 2008.

20. Caramalho I, Lopes-Carvalho T, Ostler D, et al: Regulatory T cells selectively express toll-like receptors and are activated by lipopolysaccharide. J Exp Med 197: 403-411, 2003.

21. Khattri R, Cox T, Yasayko SA and Ramsdell F: An essential role for Scurfin in CD4+CD25+ T regulatory cells. Nat Immunol 4: $337-342,2003$

22. Hori S, Nomura T and Sakaguchi S: Control of regulatory T cell development by the transcription factor Foxp3. Science 299: 1057-1061, 2003

23. Sakaguchi S, Wing K, Onishi Y, Prieto-Martin P and Yamaguchi T: Regulatory T cells: how do they suppress immune responses? Int Immunol 21: 1105-1111, 2009.

24. Huber S, Schramm C, Lehr HA, et al: Cutting edge: TGF-beta signaling is required for the in vivo expansion and immunosuppressive capacity of regulatory $\mathrm{CD} 4{ }^{+} \mathrm{CD} 25^{+} \mathrm{T}$ cells. $\mathrm{J}$ Immunol 173: 6526-6531, 2004

25. Molling JW, de Gruijl TD, Glim J, et al: CD4 $\left({ }^{+}\right) \mathrm{CD} 25$ hi regulatory T-cell frequency correlates with persistence of human papillomavirus type 16 and T helper cell responses in patients with cervical intraepithelial neoplasia. Int J Cancer 121: 1749-1755, 2007.

26. Sun J, Walsh M, Villarino AV, et al: TLR ligands can activate dendritic cells to provide a MyD88-dependent negative signal for Th2 cell development. J Immunol 174: 742-751, 2005.

27. Kaisho T, Hoshino K, Iwabe T, Takeuchi O, Yasui T and Akira S: Endotoxin can induce MyD88-deficient dendritic cells to support T(h)2 cell differentiation. Int Immunol 14: 695-700, 2002.

28. Bais AG, Beckmann I, Lindemans J, et al: A shift to a peripheral Th2-type cytokine pattern during the carcinogenesis of cervical cancer becomes manifest in CIN III lesions. J Clin Pathol 58: 1096-1100, 2005. 